\title{
Dermatofibrosarcoma Protuberans of The Face: A Case Report And Review of The Literature
}

\author{
Ilson Sepulveda ${ }^{1}$, Alex Urra ${ }^{2}$, JoaquínUlloa ${ }^{2}$, Pablo Mucientes ${ }^{3}$, Pamela Villalobos ${ }^{4}$, Cesar García ${ }^{5}$ and Felipe \\ Fredes $^{6}$ \\ ${ }^{1}$ Department of Radiology, General Hospital of Concepcion, Chile
}

${ }^{2}$ ENT-Head and Neck Surgery Service, General Hospital of Concepcion, Chile

${ }^{3}$ Department of Pathology, General Hospital of Concepción, Chile

${ }^{4} \mathrm{MD}$ Anderson Cancer Center, USA

${ }^{5}$ Department of Radiotherapy, General Hospital of Concepcion, Chile

${ }^{6}$ ENT-Head and Neck Surgery Service, University of Concepcion School of Medicine, Chile

Submission: February 02, 2017; Published: February 21, 2017

"Correspondence Address: Department of Radiology, ENT-Head and Neck Surgery Service, General Hospital of Concepcion, San Martin Av 1436, Chile, Email: isepulvedaguilar@gmail.com

\begin{abstract}
We report on a patient who presented on the ear, nose and throat (ENT) clinic with swelling on the right temporal region. Imaging studies revealed an expansive process of the skin and subcutaneous tissues of the right preauricular region. Post intravenous contrast administration revealed an ovoid mass with high enhancement without affecting the parotid gland. The patient underwent tumor resection, and a biopsy confirmed the presence of a Dermatofibrosarcoma Protuberans (DFSP). In addition, as part of the treatment the patient received radiation therapy and is currently disease-free without signs of recurrence.
\end{abstract}

Keywords: Dermatofibrosarcoma; Protuberans; Local; Recurrence; Soft; Tissue; Sarcoma; CT; Surgery; Radiotherapy

\section{Introduction}

Dermatofibrosarcomaprotuberans (DFSP) is a soft tissue neoplasm that usually arise from skin or subcutaneous tissue, characterized by a protuberant growth pattern, local recurrence after surgery, rare distant metastases and is classified as a sarcoma of low-grade malignancy [1]. It was first recognized by Taylor [2] in 1890, and described by Derriere [3] in 1924, but the term "Dermatofibrosarcoma Protuberans" was coined by Hoffman [4] in 1925. DFSP are most commonly found on the trunk, followed by the extremities and the head and neck [5]. Here we present a case of a Dermatofibrosarcoma Protuberans of the temporal region.

\section{Case Report}

A 64-year-old female patient, with a history of right parotid tumor operated in 2002, presented in the otolaryngology service in the year 2011 with a 4-year painless mass in the right temporal region. Physical examination shows a 3 centimeters $(\mathrm{cm})$ ovoid mass of cystic consistency, painless, in the right temporal region, above the auricle. The tumor, of approximately $5 \mathrm{~cm}$, was resected and the biopsy informs a Dermatofibrosarcoma Protuberans with compromised resection margins.
The case was presented and discussed at the Head and Neck Tumor Board (HNTB). The HNTB recommended to extend the surgical margins. During the waiting period for surgery, the neoplastic had recurred presenting a $6 \mathrm{~cm}$ tumor in the right preauricular region, extending to the right molar region with palpebral posies and ipsilateral facial palsy.

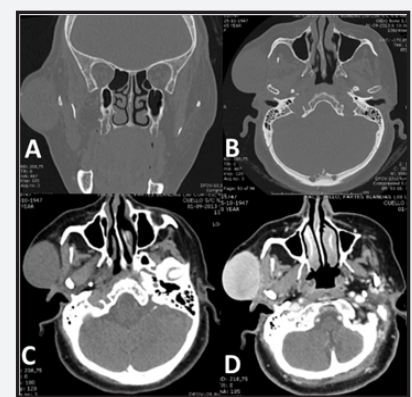

Figure 1: CT scan showing an ovoid expansive process of the right masticatory space, isodense, well delimited, without infiltrative bony compromise. High and homogeneous enhancement after intravenous contrast injection. Not observed central hypotenuses areas of necrosis or cystic degeneration. A. Bone window coronal view. B bone window axial view; C. Soft tissue window axial view; D. Soft tissue window post intravenous contrast injection axial view. 


\section{Cancer Therapy \& Oncology International Journal}

Acomputed tomographyscan(Figure1) was performed showing an ovoid, well delimited expansive process with involvement of the skin and subcutaneous tissue of the right preauricularregion, which contacts the surface of the parotid. The lesion measures approximately $36 \times 40 \times 52 \mathrm{~mm}$. No cervical adenopathy or lesions suggestive of distant metastases were evident.

The patient underwent wide surgical resection of the tumor with a margin of 2-3 cm where possible. This treatment option was chosen due to the lack of access to Mohs' micrographic surgery (MMS). Theintraoperative biopsy confirmed the presence of surgical margins free of neoplastic. In addition, a nodule of $2 \mathrm{~cm}$ in the masseter and two lymph nodes in the ipsilateral level IIA were observed during the procedure. The nodule was resected and a selective neck dissection of the right, IIAganglionic level was performed, with intraoperative biopsies being negative for neoplastic. The surgical defect was reconstructed with a cervicofacial flap.

Histopathological examination of the completely excised tumor revealed a highly cellular tumor consisting of spindle cells arranged in storiform pattern. The immunohistochemical staining was strongly positive for CD34, confirming the diagnosis of a "Dermatofibrosarcoma Protuberans" (Figure 2). All margins were free of neoplastic. The dissected lymph's nodes were negative for neoplastic.

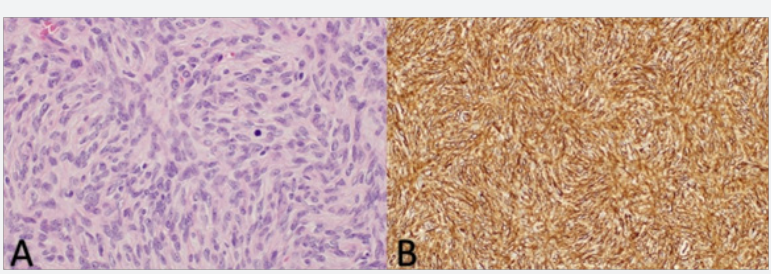

Figure 2: Immunohistochemistry study (20x) A Hematoxylin \& Eosin stain. B. Positive CD34 stain

It was decided in the HNTB to complete the treatment with postoperative radiotherapy, receiving a total of 60 Gy in 6 weeks. At the 38-month follow-up, the patient does not show signs of local recurrence, but persists with facial palsy and right palpebral posies.

\section{Discussion}

Dermatofibrosarcoma Protuberans (DFSP) is an aggressive skin malignant neoplasm, with by high rate of local recurrence and low metastatic potential [5]. DFSP is a rare tumor, with an overall incidence of 0.8 to 5 per million inhabitants [6]. They mainly affect adult, although the age range is wide (20 - 50 years) with a slight male predominance [6]. Are most commonly found on the trunk (42-72\%) and extremities (16-30\%), followed by the head and neck (10-16\%) [7]. It represents the most frequent skin sarcoma [8].

Almost $85-90 \%$ of all DFSPs are low-grade tumors. The remaining $10-15 \%$ contains a component of high-grade fibro sarcoma. This characteristic, present in more than $5 \%$ of tumor volume, determines a high incidence of local relapse and distance metastasis [5].
More than $90 \%$ of DFSP present reciprocal chromosomal translocation between chromosomes 17 and 22, t (17;22) [9]. This fuses the strongly expressed collagen 1-Alpha-1gene (COL1A1) on chromosome 17 with the platelet derived growth factor (PDGF-B) gene on chromosome 22. Like result of this, it is produce anticrime activation of the platelet derived growth factor receptor tyrosine kinase (PDGF-R) which generates the proliferation of DFSP tumor cells [9].

DFSP grows slowly, ranging from several months to many years. Initially appears as an indurate plaque, mostly reddish brown or light blue, later developing into a nodule in the plaque. It is usually asymptomatic and telangiectasias can be seen in surface. The tumor is usually solitary and relapsed cases often show lobulated or multiple nodules. The tumors borders are frequently clear [10].

The imaging findings for DFSP are nonspecific and is characterized by a subcutaneous well-defined soft tissue nodule or mass on CT and MRI, showing intermediate-to-high enhancement on contrast-enhanced studies [11]. Microscopically it is characterized by the present of spindle-shaped tumor cells, with a characteristic finger-like pattern of infiltration into the subcutaneous fat [12]. Immunohistochemical staining demonstrates strong positivity for CD34 and vimentin [5].

DFSPs, for being an extremely aggressive malignance with tendency to invade surrounding tissue, the treatment of choice is wide and deep local excision (WLE), with $3 \mathrm{~cm}$ margins beyond the tumor including the underlying fascia [5]. Reports shows that only $58 \%$ of patients had negative microscopic margins after excision [13]. For obtain free margin the tumor and preserve the uninvolved tissue from resection, some authors suggest the use of Mohs' micrographic surgery (MMS) [14]. Classic technique requires continuing sequential horizontal sectioning during resection and immediate, frozen, microscopic examination, until free margin is obtained [15]. The actual WLE technique plus reconstruction of the surgical defect can achieve margins free of neoplastic negative in nearly $90 \%$ of the cases [16]. Paradise et al. [17] established a $13.2 \%$ local recurrence rate with WLE and none with MMS. A review of the literature made by the same author, showed a $1.3 \%$ recurrence rate for MMS versus $20.7 \%$ for WLE.

DFSP is a radiosensitive tumor. Adjuvant radiotherapy is indicated in case of margin invasion or when extend surgical margins is not possible due to anatomic limitations. The suggested treatment is 60-70 Gy depending if the remaining tumor is micro or macroscopic [18]. Chemotherapy is ineffective [5]. Recently studies about targeted therapy, showed excellent results in disseminated cases. Imatinibmesylate, a selective tyrosine kinase inhibitor, can inhibit PDGFR tyrosine kinase. This drug can be used in unresectable tumors and in locally advanced, recurrent or metastatic disease [19].

The main prognostic factor for recurrence is incomplete resection of the tumor1. Metastasis are rare and are present in $0.4 \%$ to $1.1 \%$ of cases $[20,21]$. The rate of distant 


\section{Cancer Therapy \& Oncology International Journal}

metastases of DFSP with fibrosarcomatous transformation or fibrosarcomatousdermatofibrosarcomaprotuberans is round $10-15 \%$ and poorer prognosis compared with DFSP without fibrosarcomatous transformation [22]. The 5-year relative survival rates for reported in all population-based studies are can reach up to $100 \%$ [23] (Figure 3).

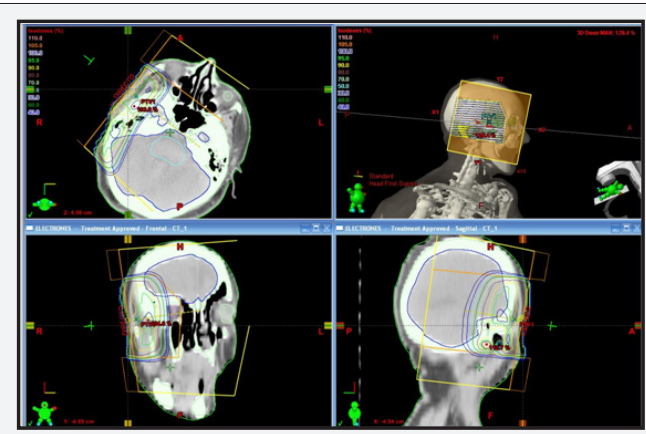

Figure 3: 3-Dimentional conformal radiotherapy plan.

\section{Conclusion}

DFSP is a rare skin malignancy with a high rate of local recurrence but rarely metastatic. The treatment consists in complete resection of the tumor. Wide local excision with 2-3 cm margin and Mohs' Micrographic Surgery are the most frequent alternatives to treat DFSP and to reduce the local recurrence. The head and neck is a challenging area due to critical structures and aesthetic difficulties in reconstruction.

\section{References}

1. Hayakawa K, Matsumoto S, Ae K, Tanizawa T, Gokita T, et al. (2016) Risk factors for distant metastasis of dermatofibrosarcoma protuberans. J Orthopaed Traumatol 17(3): 261-266.

2. Taylor RW (1890) Sarcomatous tumors resembling in some respects keloids. Arch Dermatol 8: 384-387.

3. Darrier J, Ferrand M (1924) Dermatofibromes progressifs et recidivants ou fibrosarcomes de la peau. Ann DermatolSyphiligr (Paris) 5: 545562

4. Hoffman E (1925) Uber das knollentreibende fibrosarkom der haut. Dermatol

5. N Angouridakis, P Kafas, W Jerjes, Stefanos Triaridis, Tahwinder Upile et al. (2011) Dermatofibrosarcomaprotuberans with fibrosarcomatous transformation of the head and neck. Head \& Neck Oncology 3: 5-7.

6. Zheng Z, Piao J, Lee J, Kim S, Kim S, et al. (2015) Dermatofibrosarcoma Protuberans: A Study of Clinical, Pathologic, Genetic, and Therapeutic Features in Korean Patients. Yonsei Med J 56(2): 440-446.

7. Lemm D, Mugge LO, Mentzel T, Hoffken K (2009) Current treatment options in Dermatofibrosarcoma protuberans. J Cancer Res ClinOncol 135(5): 653-665.
8. Stojadinovic A, Karpoff HM, Antonescu CR, Shah JP, Singh B, et al (2000) Dermatofibroma protuberance of the head and neck. Ann Surg Oncol 7(9): 696-704.

9. Sirvent N, Maire G, Pedeutour F (2003) Genetics of dermatofibrosarcomaprotuberans family of tumors: from ring chromosomes to tyrosine kinase inhibitor treatment. Genes Chromosomes Cancer $37(1): 1-19$

10. Llombart B, Serra-Guille 'n C, Monteagudo C, López Guerrero JA, Sanmartín O (2013) Dermatofibrosarcoma protuberans: a comprehensive review and update on diagnosis and management. Semin Diagn Pathol 30(1): 13-28.

11. Zhang L, Liu QY, Cao Y, Zhong JS, ZhangWD (2015) Dermatofibrosarcoma Protuberans: Computed Tomography and Magnetic Resonance Imaging Findings. Medicine 94(24): e1001.

12. Larbcharoensub N, Kayankarnnavee J, Sanpaphant S, Kiranantawat K, Wirojtananugoon C, et al. (2016) Clinicopathological features of Dermatofibrosarcoma Protuberans. OncolLett 11(1): 661-667.

13. Bowne WB, Antonescu CR, Leung DHY, Katz SC, Hawkins WG, et al. (2000) Dermatofibrosarcoma protuberans. A clinicopathologic analysis of patient treated and followed at a single institution. Cancer 88(12): 2711-2720.

14. Lemm D, Mügge LO, Mentzel T, Höffken K (2009) Current treatment options in Dermatofibrosarcoma protuberans. J Cancer Res Clin Oncol 135(5): 653-665.

15. Salomon D, Adatto M, Skaria AM (2006) Mohs micrographic surgery: concept, technic and indications. Rev Med Suisse 2(63): 1094-1099.

16. Fiore M, Miceli R, Mussi C, Lo Vullo S, Mariani L, et al. (2005) Dermatofibrosarcoma protuberance treated at a single institution: A surgical disease with high cure rate. J Clin Oncol 23(30): 7669-7675.

17. Paradisi A, Abeni D, Rusciani A, Cigna E, Wolter M, et al. (2008) Dermatofibrosarcomaprotuberans: wide local excision vs. Mohs micrographic surgery. Cancer Treat Rev 34(8): 728-736.

18. Ugurel S, Kortmann RD, Mohr P, Mentzel T, Garbe C, et al. (2008) Short German guidlines. Dermatofibrosarcoma protuberans. J Dtsch Dermatol Ges 6(1): S17-S18.

19. Han A, Chen E, Niedt G, Sherman W, Ratner D (2009) Neoadjuvantimatinib therapy for dermatofibrosarcomaprotuberans. Arch Derm 145(7): 792-796.

20.Gloster HM (1996) Dermatofibrosarcoma protuberans. J Am Acad Dermatol 35(3 pt 1): 355-374.

21. Cai H, Wang Y, Wu J, Yingqiang Shi (2012) Dermatofibrosarcomaprotuberans: clinical diagnoses and treatment results of 260 cases in China. J Surg Oncol 105(2): 142-148.

22. Abbott JJ, Oliveira AM, Nascimento AG (2006) The prognostic significance of fibrosarcomatous transformation in dermatofibrosarcomaprotuberans. Am J Surg Pathol 30(4): 436-443.

23. Rouhani P, Fletcher CD, Devesa SS, Toro JR (2008) Cutaneous soft tissue sarcoma 
This work is licensed under Creative Commons Attribution 4.0 License

DOI:10.19080/CTOIJ.2017.03.555606
Your next submission with Juniper Publishers will reach you the below assets

- Quality Editorial service

- Swift Peer Review

- Reprints availability

- E-prints Service

- Manuscript Podcast for convenient understanding

- Global attainment for your research

- Manuscript accessibility in different formats

( Pdf, E-pub, Full Text, Audio)

- Unceasing customer service

Track the below URL for one-step submission https://juniperpublishers.com/online-submission.php 